\title{
LIMITES ENTRE A LIBERDADE DE EXPRESSÃ OCONSTITUCIONAL RELIGIOSA, O CHARLATANISMO RELIGIOSO E O CURANDEIRISMO
}

\section{LIMITS BETWEEN RELIGIOUS CONSTITUTIONAL FREEDOM OF EXPRESSION, RELIGIOUS CHARLATANISM AND HEALING}

\author{
Elvis Gomes Marques Filho ${ }^{1}$ \\ Eliana Pereira de Carvalho ${ }^{2}$ \\ Jose Evanilson de Sousa Barros ${ }^{3}$
}

\section{RESUMO}

Este artigo tem como objeto a liberdade de expressão religiosa e como objetivo geral a análise dos limites da liberdade de expressão constitucional nas manifestações de curandeirismo e de charlatanismo religioso. De início, é apresentada uma abordagem histórica quanto a busca da religião pelo ser humano para o tratamento de doenças físicas e mentais, mostrando, assim também, a evolução das práticas de cura e a sua desassociação com o misticismo. Em seguida é trazida uma abordagem legal e bibliográfica quanto à liberdade religiosa sob a ótica constitucional e quanto aos crimes de curandeirismo e de charlatanismo. Ainda, é traçada uma linha tênue entre o que é considerado exercício de liberdade religiosa e o que se configura enquadrado em ilícito penal. Como conclusões deste estudo, em regra, as práticas curativas de comunidades tradicionais não se enquadram como crimes e representam direitos humanos de natureza cultural. Quanto à metodologia, adotou-se o método dedutivo, utilizando-se de pesquisas bibliográficas em artigos científicos, doutrinas e dispositivos legais.

Palavras-Chave: Charlatanismo. Curandeirismo. Saúde. Religião. Liberdade.

\section{ABSTRACT}

The object of this article is present the freed om of religious expression and the analysis of its constitutional limits in the manifestation of witch-doctoring and charlatanism. Initially, a historical approach is presented regarding the search by the human beings for treatment of physical and mental illnesses through religion, also showing the evolution of healing practices and their disassociation with mysticism. Next, a legal and bibliographic approach is presented about religious freedom from a constitutional perspective considering the crimes of witch-doctoring and charlatanism. In addition a thin line is drawn between what is considered an act of religious freed om and what constitutes a criminal offence. Concluding the research, the healing practices of traditional communities are not classified as crimes and represent human rights of a cultural nature, as a rule. About the method ology, the deductive method was adopted, using bibliographic research on scientific articles, doctrines and legal provisions.

\footnotetext{
${ }^{1}$ Mestrando em Direitos Humanos pela Universidade Federal do Mato Grosso do Sul. Especialista em Direitos Humanos pela Faculdade Adelmar Rosado. Professor efetivo do curso de Direito da Universidade Estadual do Piauí.

${ }^{2}$ Doutora em Letras pela Universidade Estadual do Rio Grande do Norte. Mestra em Letras, concentração em Estudos Literários, pela Universidade Federal do Piauí. Professora efetiva do curso de Letras da Universidade Estadual do Piauí e da Secretaria de Estado da Educação do Piauí.

${ }^{3}$ Graduando em Direito pela Universidade Estadual do Piauí.
} 
Keywords: Witch-d octoring. Healing. Health. Religion. Freedom.

\section{INTRODUÇÃO}

Segundo Durkheim (2003, p. 32), a religião pode ser definida como "um sistema solidário de crenças e de práticas relativas a coisas sagradas, isto é, separadas, proibidas”. Em decorrência disso, a comunhão de tais crenças e práticas implica a existência de uma mesma comunidade moral que concentre, em determinado espaço, igreja ou templo, todos aqueles que compartilhem desse sistema solidário. A importância da religião não é fruto estritamente da sociedade moderna, pois, com um curto olhar ao longo da história do homem, nota-se a constante ligação humana às crenças religiosas em todas as épocas.

O Estado brasileiro é laico, logo não adota nenhuma religião como oficial, conforme assegura o art. 19, inc. I da Constituição Federal de 1988. A Lei Maior ainda garante o exercício de cultos religiosos, como também a liberdade de crença e de consciência. Muitas vezes, os atos de fé e devoção demonstram ser inofensivos à vida privada ou coletiva, porém, em alguns casos, líderes religiosos utilizam-se da fé das pessoas para praticar atos lesivos ao patrimônio e à saúde. Frente a tais formas de exploração da fé das pessoas, o legislador penal não foi omisso e elencou crimes contra a saúde pública, em especial, o charlatanismo e o curandeirismo.

Roy Porter (2008, p. 13) esclarece que, no decurso da história, é possível observar que as diversas mitologias religiosas trazem consigo explicações, geralmente de maneira simplificada, para fenômenos naturais e metafísicos, o homem recorreu a religião para solucionar seus problemas, inclusive os de natureza física, muitas pessoas passaram a se aproveitar dos momentos de fragilidade para se beneficiarem.

É importante pontuar, de início, que o Estado contemporâneo respeita as liberdades religiosas, porém impõe limites para tais liberdades. Um deles é a punibilidade daqueles que fazem mau uso da religião, utilizando-a como instrumento para granjear vantagens em benefício próprio. O legislador penal brasileiro criou dois delitos que visam garantir a não violação da saúde pública pelas religiões; são eles o charlatanismo religioso e o curandeirismo. Entretanto, o poder público também deve levar em consideração que o Estado não consegue chegar a toda a população, pois há povos tradicionais possuem a religião como única forma de tratamento para suas patologias.

Neste contexto, o presente estudo busca analisar a liberdade de expressão constitucional religiosa e o que a separa do charlatanismo e do curandeirismo. Esta pesquisa utilizou-se da 
metodologia dedutiva e teve como base pesquisas bibliográficas, artigos científicos nacionais e internacionais, análises doutrinárias e legislativas.

\section{AS INTERSECCIONALIDADES ENTRE AS PRÁTICAS CURATIVAS E A RELIGIÃO}

Ante a inércia do Estado, a respeito de questões de saúde pública, as religiões avocaram tais questões e, durante muito tempo, foram as únicas alternativas dos indivíduos para o tratamento de seus problemas físicos e mentais. Por isso é importante analisar a evolução das ciências médicas e as suas relações com as religiões no transcorrer da história.

Porter (2008, p. 223) aponta que os povos do Egito Antigo, em torno de (1500 - 1600 a.C.), já tratavam de práticas curativas e uso de drogas para tratamentos, entretanto os hieróglifos são de difícil interpretação, dificultando assim a descrição de quais substâncias eram utilizadas. Porém, constatou-se que eles atribuíam virtudes medicinais a resinas (olíbano, mirra, maná, etc.), utilizavam plantas como purgativos (sena, colocíntida, óleo de castor, etc.), além de partes de animais das mais variadas formas terapêuticas, como as gorduras de bois, pele de porcos e até mesmo cérebros de cágados.

Aindaé ressaltado por Porter (2008, p. 224) que os egípcios se destacaram por criar as “casas de vida", templos utilizados como local para tratamento de doenças, que são entendidas como as primeiras instituições médicas. Os curandeiros egípcios se destacaram por suas especialidades, posto que cada curandeiro era responsável somente pelo tratamento de uma doença. As práticas egípcias foram reproduzidas pelos povos da Assíria e da Babilônia.

Na Mesopotâmia, os tratamentos também eram realizados nos templos. De acordo com os esclarecimentos de Silva (2009, p. 842-843), as doenças eram consideradas consequências de um castigo divino ou eram resultantes de influências malignas. Nesse período, a medicina começava a ser preventiva, era pregado o uso de amuletos apropriados e oferendas ou sacrifícios eram realizados como apaziguadores das forças malignas. Houvera também diversos avanços nas ciências biológicas, cabendo destacar a utilização de diagnósticos, prognósticos e exames físicos na detecção de doenças.

Para Silva (2009, p. 852), o Código de Hamurabi (1948 - 1905 a. C.) foi quem primeiro definiu o conceito de responsabilidade civil e criminal do médico. Se o médico efetuasse uma operação importante ou curasse uma doença, receberia dez moedas de prata. Se o paciente fosse um homem livre, deveria pagar cinco moedas. Caso fosse um escravo, seu dono deveria pagar dez 


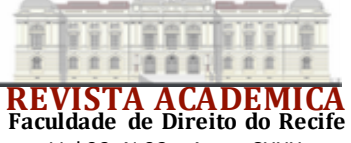

Vol.93 N.02 - Anno CXXX

moedas. Caso o paciente morresse ou sofresse uma grave lesão teria suas mãos decepadas como pena.

A abordagem mais crítica das ciências biológicas se desenvolveu na civilização grecoromana, como ressalta Porter (2008, p. 224), já que passaram a se basear de maneira mais intensa na observação e na experiência. Conforme o autor, muito desse mérito deve ser dado a Hipócrates de Cós (470 - 377 a.C.) e seus seguidores que, ao visitarem a China, passaram a dedicar-se ao estudo anatômico e a medicina humoral como tratamento das patologias, buscando também a substituição das drogas por mudanças de hábitos alimentares e de estilo de vida. É pontuado também que Hipócrates já separava a medicina da religião, pois reconhecia que as doenças eram resultantes de fatores naturais.

Miranda (2017, p. 21) dita que em toda a Grécia foram construídos inúmeros templos dedicados ao culto do deus Asclépio, que exerciam a função de centros de aconselhamento médico, prognóstico e de cura. Nesses locais, os pacientes entrariam em um estado de sono induzido conhecido como enkoimesis e lá receberiam orientações da divindade em um sonho ou eram curados por cirurgias, já que este estado funcionava como uma espécie de anestesia. A terapêutica utilizada era constituída de dietas leves à base de frutas e de banhos prolongados, acompanhados pela prática de sacrifício de animais. Também é apontado que os romanos se destacaram pela utilização de instrumentos cirúrgicos como agulhas, pinças, bisturis, tesouras etc.

Miranda (2017, p. 22) ressalta que o maior nome romano no que tange às ciências naturais foi Cláudio Galeno (129 - 199 d.C.). Dentre suas contribuições, cabe destacar o seu famoso axioma, "os contrários curam os contrários"; como, por exemplo, o emprego de água fria contra queimaduras e o de purgantes contra prisão de ventre. $\mathrm{O}$ estudioso esclarece que, na Europa Medieval (séc. V-XV), houve pouco progresso científico. Em decorrência, as doenças voltaram a ser atribuíd as a causas divinas e a população buscava a cura de suas patologias em igrejas dedicadas aos mais diversos santos.

Na Idade Média, Miranda (2017, p. 22) esclarece que a peste negra (peste bubônica) matou milhões de pessoas e era tida pela população como um castigo divino. Contudo, a experiência dessa pandemia acarretou na ad oção de medidas importantes de saúde pública, como, por exemplo, nas grandes cidades, como em Veneza e Florença, houve a criação de comitês de saúde pública. Também é apontado que, apesar da ausência de espírito crítico, os monges medievais copiaram, preservaram e estudaram os escritos médicos acumulados durante toda a Antiguidade. Foram os árabes que impulsionaram a medicina neste período, porém o islamismo os restringia de certas 


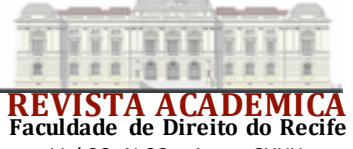

Vol.93 N.02 - Anno CXXX

práticas, a exemplo das dissecações de cadáveres humanos, incorrendo na limitação do avanço de ciências como a anatomia e a fisiologia.

No Renascimento (séc. XVI - XVII), houve um notável salto no conhecimento, como defende Miranda (2017, p. 22). Com o método científico, foi possível chegar a conclusões através da coleta de observações e experimentos. Outrossim, a divulgação científica foi ampliada graças à impressão.

A Reforma Protestante desencadeia as guerras religiosas firmadas na intolerância, que se relacionam com o advento do Estado Moderno. Ele é soberano como solução política para os conflitos teológicos, permitindo assim também a ascensão das ciências, firmando ideários que iriam influenciar a Constituição dos Estad os Unidos, assim como tod o o ocidente (CANOTILHO et al., 2018, p. 543).

Segundo Margotta (1988, p. 122), a medicina moderna foi evoluindo ao longo dos séculos, com contribuições mais ou menos importantes que ajudaram a compor o escopo dos conhecimentos de que dispomos hoje. Durante muito tempo, tornou-se impossível desassociar a religião das demais instituições sociais. Isso porque os líderes religiosos assumiram também um papel político e influenciavam assim diretamente o Estado em todos os seus campos de atuação desde a educação, a saúde e até mesmo na criação, na execução e no julgamento das leis. A laicidade do Estado permitiu a separação da religião das demais instituições sociais, garantindo, assim, uma autonomia da metodologia científica.

Villa (2011, p. 20) aponta que a liberdade de crença possui como marco inicial no Brasil a Constituição de 1891, posto que houve a transição da monarquia para o sistema republicano, ocasionando na separação entre igreja e Estado e deixando, assim, de existir uma religião oficial brasileira. O Estado, por sua vez, passou a ser laico.

De acord o com Mendes e Branco (2021, p. 447), o atual Documento Constitucional expressa a neutralização estatal quanto à liberdade religiosa, já que houve a positivação da liberdade de crença e da de escusa de consciência. Logo, as igrejas deixaram de interferir nas ciências, permitind o um salto no conhecimento científico brasileiro.

\section{LIBERDADE RELIGIOSA CONSTITUCIONAL}

O direito à liberdade religiosa é definido por Bobbio (2004, p. 14) como o direito a professar qualquer religião ou a não professar nenhuma. Quanto ao conceito jurídico de religião, 
Canotilho et al. (2018, p. 543) esclarecem que deve ser usada a abordagem tipológica, posto que ela é ampla e não essencialista, partindo de elementos comuns e relativamente consolidados, como, por exemplo, a existência de famílias. Com isso, realiza-se uma análise de similitude com os padrões mais estabelecidos do fenômeno religioso, excluindo assim as visões de mundo ideológicas, filosóficas, agnósticas ou ateias. É ressaltado também que a expressão "seita" não possui contorno jurídico, é de viés pejorativo e potencialmente discriminatório.

A Declaração Universal Dos Direitos do Homem (DUDH), de 1948, em seu art. 18, dita que toda a pessoa tem direito à liberd ade de pensamento, de consciência e de religião, implicando assim na ampla liberdade de mudança e manifestação de religião ou até mesmo de convicção, tanto em âmbito público como em privado, pelo ensino. Do ponto de vista de Panasiewicz (2010, p. 127), a DUDH instituiu o pluralismo religioso que permitiu a expressão da religiosidade do ser humano em busca de um sentido de vida.

Gimenes (2015, p. 146) pontua que o Estado laico deve sempre buscar ser neutro e imparcial nas questões religiosas, entretanto deve, ao máximo, se afastar da hostilidade, pois assim poderá ajudar os indivíduos a exercer a racionalidade prática, orientada para a tomada de decisões pessoais que busquem contribuir para garantir uma saudável convivência em sociedade; o que, segundo o autor, o Estado sozinho não consegue fazer, embora o faça em parte.

Mendes e Branco (2012, p. 448) afirmam que a liberdade de pensamento é um Direito fundamental de primeira geração; o que torna possível a exteriorização da crença religiosa pelos indivíduos. Segundo Morais (2011, p. 228), a liberdade de consciência materializa a laicidade do Estado, pois assegura a inviolabilidade de consciência e de crença. Para isso, o Estado tem que atuar como garantidor do "livre exercício dos cultos religiosos" e da "proteção aos locais de cultos e a suas liturgias".

É observado por Morais (2011, p. 229) que a autonomia quanto à consciência é bastante ampla, posto que liberta o indivíduo de quaisquer interferências de ordem moral, filosófica, religiosa, política ou sociológica, permitindo assim que cada qual escolha e adote uma linha de pensamento, conforme suas particularidades. Ao cidadão também é assegurado o Direito á escusa de consciência que consiste em o indivíduo se eximir de cumprir uma obrigação a todos imposta, alegando motivos de natureza filosófica, política ou religiosa. Todavia, em contrapartida, o indivíduo terá que cumprir prestações alternativas e, caso não cumpra, perderá assim seus Direitos políticos. 


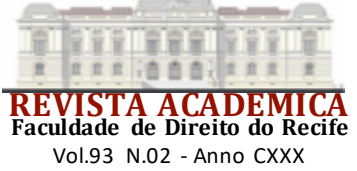

Na liberdade religiosa inclui-se a liberdade de organização, logo o poder público não pode intervir na autonomia e na economia interna das associações religiosas. Não pode, por exemplo, impor a igualdade de sexos na entidade ligada a uma religião que não a acolha. De acordo com Mendes e Branco (2021, p. 448), para evitar que o Estado crie restrições à liberdade de religião, o constituinte estabelece a imunidade de impostos sobre templos de qualquer culto, conforme o art. 150, VI, b, do Texto Magno.

Moraes (2018, p. 88) esclarece que a abrangência do preceito constitucional é ampla, posto que, sendo a religião o complexo de princípios que dirigem os pensamentos, as ações e a adoração do homem para com Deus, ela acaba por compreender a crença, o dogma, a moral, a liturgia e o culto. Pontua também que constrangimento ao ser humano de forma a renunciar sua fé representa o desrespeito à diversid ade democrática de ideias, de filosofias e d a própria diversidade espiritual. Obviamente, assim como as demais liberdades públicas, também a liberdade religiosa não atinge grau absoluto, não sendo, pois, permitidos, a qualquer religião ou culto, atos atentatórios à dignidade da pessoa humana, sob pena de responsabilização civil e criminal.

A liberdade de crença é conceituada, por Agra (2018, p. 216), como a credulidade na existência de seres que não têm uma vida terrena palpável, pois são metafísicos, como anjos, fadas, deuses, duendes etc. Agra (2018, p. 217) ainda esclarece que Direito de culto se difere de Direito a liturgia, já que o primeiro garante a manifestação religiosa e o segundo diz respeito aos atos utilizados pelas pessoas para entrar em contato com suas divindades. Cabe citar a missa como um exemplo de culto e os cantos e a eucaristia como exemplos de liturgias. É derivante da liberdade de culto a possibilidade de obtenção, em certos casos, de assistência religiosa, gerando um dever prestacional para o Estado, já que o art. $5^{\circ}$, inc. VII, garante a prestação de assistência religiosa nas entidades civis e militares de internação coletiva, como por exemplo em presídios e nos quartéis.

Agra (2018, p. 218) define como limite à liberdade de culto, o respeito ao direito à paz da vizinhança, não se podendo, por exemplo, fazer barulho que atrapalhe o descanso alheio. Já os limites da liberdade de crença residem nos direitos fundamentais da pessoa e na lei de proteção aos animais. Com essa medida, pretende-se evitar o sacrifício e maus-tratos físicos tanto de seres humanos quanto de animais, devendo sempre ser levado em consideração os princípios da razoabilidade e da alteridade. $\mathrm{O}$ conceito de religião, ademais, liga-se à pré-compreensão que o termo propicia, a referi-lo a um sistema de crenças em um ser divino, em que se professa uma vida além da morte, que possui um texto sagrado, que envolve uma organização e que apresenta rituais de oração e de adoração. 


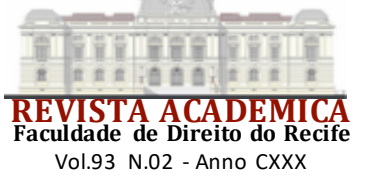

Canotilho et al. (2018, p. 545) apontam que, como restrições e limites à liberdade religiosa, não há, no caso brasileiro, previsão explícita no plano constitucional de qualquer restrição legal, o que é coerente com a íntima proximidade com a dignidadeda pessoa humana. Foi conferido assim, pelo Texto Maior, perímetro alargado à liberdade religiosa, que não pode ser suspensa no estado de defesa ou sequer no estado de sítio (arts. 136 e 139 da Constituição).

Entretanto, Canotilho et al. (2018, p. 545) esclarecem que os limites implícitos da liberdade religiosa estão presentes em face da necessidade de compatibilizar com os direitos de terceiros e com outros bens constitucionais. Observa-se que as restrições também serão submetidas aos limites dos limites (a lei limitadora, interpreta-se segundo o programa do direito fundamental objeto de restrição, sendo limitad a na sua eficácia limitadora), ao crivo da proporcionalidade e, por fim, à garantia do núcleo essencial do direito à liberdade.

É comum que as pessoas se utilizem da liberdade religiosa para cometer crimes. Puttini (2011, p. 34) aponta que, quando se objetiva, através do crime, atingir indivíduos determinados será considerado delito contra a pessoa. Porém, quando se busca atingir um número indeterminado de indivíduos, incorrer-se-á em delito contra a saúde pública. O charlatanismo e o curandeirismo são exemplos de crimes contra a saúde pública ad vindos do contexto religioso.

\section{CHARLATANISMO}

Conforme Mehlman (2005, p. 350), o charlatanismo (quackey, em inglês) deriva da palavra quacksalver, que significa aquele que se gaba de seus preparos. Logo, segundo o autor, um charlatão pode ser definido como aquele que finge ter habilid ades médicas e fala pretensiosamente sem ter conhecimento sobre o assunto. É apontado também que o charlatanismo se distingue da assistência médica ruim. O primeiro implica o uso de métodos que não são aceitos cientificamente, enquanto a má assistência médica é resultante da imperícia profissional, seja pelo uso indevido de diagnósticos ou de tratamentos.

Sobreira, Machad o e Vilani (2016, p. 143) apontam que, no código penal de 1890, o primeiro da república brasileira, também tinha um capítulo destinado aos crimes contra a saúde pública. Entretanto, os artigos conspiravam para criminalização das religiões de matriz africana e do espiritismo. O art. 157 previa o crime de "praticar o espiritismo" e "inculcar a cura de moléstias curáveis ou incuráveis". Já o art. 158 era mais específico em relação à terapêutica herbária religiosa, criminalizando a conduta de "ministrar ou prescrever", como "meio curativo", "substância de qualquer dos reinos da natureza". Nascimento e Martins (2020, p. 669) ainda 
ressaltam que a Constituição da República, de 1891, já assegurava a liberdade religiosa, contudo o que se via na prática era a perseguição e a punição de líderes religiosos como pais de santos e kardecistas.

Atualmente, no Brasil, o crime de charlatanismo é tipificad o no art. 283 do Código Penal e é caracterizado pela conduta de inculcar (recomendar) ou anunciar (ato de fazer propaganda, utilizando-se de meios como rádio, televisão, cartazes, internet, etc) cura de uma determinada patologia por meio secreto e infalível. A pena para tal crime é de detenção de três meses a um ano.

Segundo Sobreira, Machado e Vilani (2016, p. 143), como se trata de um crime contra a saúde pública, o sujeito passivo é a sociedade e o sujeito ativo pode ser qualquer pessoa, por se tratar de um crime comum. O elemento subjetivo é o dolo de perigo, caracterizando-se por ser um crime plurissubsistente, logo existiriam vários atos que fariam parte de uma única conduta Admitindo assim a tentativa, como a norma não dispõe sobre qual a ação penal cabível, aplica-se aquela que possui competência residual; ou seja, a pública incondicionada.

Um exemplo muito comum de charlatanismo são os camelôs que, em locais públicos, comercializam "garrafadas", alegando que elas atuam com a finalidade de combater doenças incuráveis como a AIDS e o câncer, ou até mesmo problemas corriqueiros como a impotência sexual. Puttini (2011, p. 37) ressalta que, no âmbito religioso, é difícil encontrar charlatão como caso isolado, pois, frequentemente, quem anuncia algo, acaba por ter que demonstrar a suposta eficácia da mercadoria; o que levaria ao crime de curandeirismo, se praticado habitualmente.

\section{CURANDEIRISMO}

O crime de curandeirismo é trazido no art. 284 do Código Penal. Ele é exercido pelo sujeito que prescreve (indica como remédio), ministra (fornece para que seja utilizado) ou aplica (utiliza em alguém), habitualmente, qualquer substância (de origem animal, vegetal ou mineral, ainda que não sejam nocivas para a vida humana, já que esta substância poderá retardar ou impedir o tratamento correto pelo profissional de saúde responsável), usando gestos, palavras ou qualquer outro meio (agindo de qualquer maneira que simbolize um ritual) e fazendo diagnósticos (o reconhecimento de uma doença por meio de seus sintomas e sinais característicos, este é um ato privativo do médico).

Como punição para o respectivo crime, o art. 284 estabeleceu que a pena será de detenção de seis meses a dois anos, logo o julgamento será de competência do Juizado Especial Criminal 


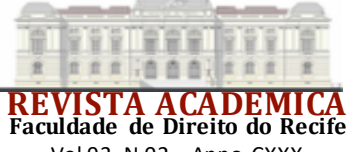

Vol.93 N.02 - Anno CXXX

(art. 61 da Lei 9.099/95), compatível com o rito sumaríssimo e também será possível a suspensão condicional do processo (art. 89 da Lei 9.099/95). Pontua-se que, caso o crime seja praticado mediante remuneração, será reconhecida a forma qualificada e ao agente também será aplicado também a pena de multa.

Silva (2019, p. 149) esclarece que o verbo “exercer" remete a uma prática habitual. Já a prática eventual de qualquer dos comportamentos previstos neste tipo, configuram-se em mero indiferente penal. É apontado também que o sujeito ativo deste tipo penal pode ser qualquer pessoa, send o um crime comum e tendo, como sujeito passivo, a socied ade.

Canotilho et al. (2018, p. 547) ressalta que a religião é um terreno propício para a prática de crimes contra a saúde pública, posto que as pessoas, muitas vezes, buscam os templos em momentos de fragilidade. Tal busca proporciona-lhes a renovação das esperanças e o alcance da cura para doenças. Por sua vez, os líderes religiosos, habitualmente, acreditam que seus meios podem curar, embora existam aqueles que só querem se beneficiar da vulnerabilidade e das crenças alheias. Aqueles que agem de boa-fé não podem assim ser julgados como criminosos.

\section{O CHARLATANISMO E O CURANDEIRISMO NO CONTEXTO RELIGIOSO}

Sarlet (2015, p. 98) pontua que a liberdade religiosa, classificada como um direito fundamental, encontra limites em outros direitos, como a dignid ade humana. Em caso de conflito, atenciosa e cuidadosa deve ser a ponderação, buscando sempre solucionar a controvérsia sem afetar o núcleo essencial do direito de liberdade religiosa, e sem esvaziar a garantia de organização religiosa.

Decorre da Carta Magna, a liberdade de escolha de tratamentos, juntamente com a liberdade de religião e seus desdobramentos (liberdade de culto e de crença). Andrade e Quintão (2011, p. 139) esclarecem que a primeira é um direito fundamental e uma manifestação do direito a personalidade. Defendem os autores que a não aceitação de determinado tratamento médico pelo paciente é um direito que não pode ser entendido como uma forma de eutanásia, tendo em vista que, em casos extremos, seria a mera aceitação da morte, dada a finitude da vida humana.

Andrade e Quintão (2011, p. 139) apontam que o consentimento para tratamentos médicos é inerente ao direito à liberdade, incluindo a liberdade de religião. Os tratamentos podem ser escolhidos pelo próprio paciente e consignados no chamado "testamento vital", que passa a ser a manifestação de vontade do paciente frente a situações em que se encontra impossibilitado de 


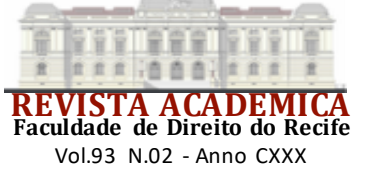

manifestá-la. Os autores ainda apontam que é um direito do paciente buscar outros métodos de tratamento, ainda que este se sustente somente na fé.

É importante retomar a distinção entre curand eirismo e charlatanismo. O primeiro pode ser definido como um crime comum que pode ser praticado por qualquer pessoa, inclusive por um médico, atuando assim como um "estelionatário da medicina" e anunciando a cura infalível de uma determinada doença, mesmo estando ciente de que seu procedimento não é idôneo para tanto. Já o curand eirismo também pode ser praticado por qualquer pessoa, porém o sujeito ativo não pode ser um médico, dentista ou farmacêutico, logo o curandeiro é um indivíduo inculto que se mete a curar com o mais grosseiro empirismo, pois acredita ser capaz de curar o enfermo, utilizando-se de receitas mágicas ou especiais.

Para Silva (2019, p. 151), o poder público deve ter bastante cautela no momento de enquadrar práticas religiosas como crimes contra a saúde pública, posto que todo movimento exercido por qualquer membro religioso que tenha a intenção de curar mazelas poderia ser abarcado pelos tipos penais. Por exemplo, padres católicos fazendo gestos da cruz e jogando água benta ou mesmo pastores que praticam exorcismo como busca pela cura. Nesses casos a ponderação deve ser utilizada, pois, como as práticas apresentam-se como inofensivas a saúde, não poderiam ser enquadradas como delituosas.

Entendem Sobreira, Machado e Vilani (2016, p. 144) que a manutenção dos artigos 283 e 284 do código penal vigente e com a atual redação, sem nenhum tipo de ressalva, é perigosa para a sociedade, posto que constitui ameaça latente àquelas práticas curativas muito comuns em religiões de tradição xamânica como, por exemplo, a umbanda. Sua prática de cura se concretiza pela prescrição de ervas por um médium em estado de transe. É pontuado ainda que as religiões tidas como minoritárias, por serem aderidas por número menor de fiéis, são as maiores vítimas do preconceito. É bastante comum a tentativa de enquadramento dos seus líderes religiosos como praticantes de charlatanismo ou de curandeirismo.

Sobreira, Machado e Vilani (2016, p. 145) propõem que os artigos 283 e 284 sejam modificados para prever, expressamente, a exclusão da ilicitude de algumas práticas religiosas, como a prescrição de ervas por médiuns, como ocorre na umbanda e no candomblé, desde que o adepto ou praticante não seja orientado, pelo médium, a abandonar qualquer tipo de terapia alopática.

Contudo, Morais (2011, p. 238) enfatiza que, mesmo nestes casos extremos, a crença religiosa daqueles submetidos a tratamentos sobrenaturais deve ser trazida à baila, condicionando 
a atuação do Direito à esfera de disponibilidade da vítima. Outrossim, pontua-se que, se a vítima tiver como resultado lesões corporais de natureza grave ou gravíssima ou até mesmo vier a óbito, o agente deverá ser responsabilizad o pelas lesões ou pelo delito de homicídio. Ele ainda reconhece que alguns líderes religiosos extrapolam os limites constitucionais assegurados à liberdade religiosa e acarretam danos à integridade física e mental ou até mesmo à vida daqueles que acreditam na cura de suas enfermidades por meios sobrenaturais.

Sarlet (2015, p. 100) aponta que os conflitos entre a liberdade religiosa e outros direitos fundamentais e bens jurídico-constitucionais são diversos, podendo assim, a depender do caso, justificar as restrições quanto ao uso da liberdade religiosa para fins de prática do curandeirismo, charlatanismo religioso e exploração da credulidade pública, principalmente quando com isso se estiver incorrendo em prática de crime ou afetando direitos de terceiros ou interesse coletivo.

Já Sobreira, Machado e Vilani (2016, p. 145) ressaltam que existe uma linha tênue entre a crença religiosa e o charlatanismo e, também, entre ela e o curand eirismo, devendo assim também ser levado em consideração a natureza das atividades praticadas, posto que, muitas vezes, são exercidas por pessoas ignorantes que acabam criando situações de incolumidade pública. Em muitos casos, até mesmo por acreditarem em seus próprios poderes milagrosos decura. Os autores apontam ainda que sempre deverá ser levada em consideração a ponderação para não enquadrar manifestações culturais como delitos penais.

\section{CLASSIFICAÇÃo JURÍdiCA dAS PRÁticas CURATIVAS DE POVOS TRADICIONAIS BRASILEIROS}

Freitas, Cohn e Pinto (2018, p. 66) esclarecem que a Constituição Federal 1988, em seu art. $6^{\circ}$, assegura o direito a saúde como um direito fund amental, logo busca garantir o acesso universal e gratuito a todos que dela necessitam, fundamentando assim o preceito de acesso gratuito e igualitário, por meio do Sistema Único de Saúde (SUS). Contudo, Sheila Borges Dourado (2012, p. 67) lembra que algumas comunidades acabam sendo excluídas, muitas vezes por questões logísticas e geográficas. Tais comunidades suprem a falta de insumos e profissionais com o ensino hereditário de práticas curativas.

Segundo Dourado (2012, p. 67), os saberes de cura de comunidades tradicionais referem-se à utilização de substâncias naturais, na maioria das vezes, ligados a expressões ritualísticas. Estes são classificados como conhecimentos tradicionais que, no entendimento de Dourado (2012, p. 67), são definidos como aqueles saberes e práticas de pessoas e de grupos, cujo modo de vida é 
considerado tradicional. São exemplos de conhecimentos tradicionais as línguas, as técnicas de artesanato, os saberes quanto a biodiversidades e quanto a ecossistemas.

$\mathrm{O}$ art. $3^{\circ}$, inc. I, do decreto 6.040/2007 (dispositivo que instituiu a política nacional de desenvolvimento sustentável dos povos e comunidades tradicionais) define povos e comunidades tradicionais como grupos culturalmente diferenciados e que se reconhecem como tais, que possuem formas próprias de organização social, que ocupam e usam territórios e recursos naturais como condição para sua reprodução cultural, social, religiosa, ancestral e econômica, utilizando conhecimentos, inovações e práticas gerados e transmitidos pela tradição.

Dourado (2012, p. 68) enfatiza que o Decreto n. 6.040/2007 segue as diretrizes da Convenção n. 169 da Organização Internacional do Trabalho (OIT), a qual preconiza a autoatribuição de uma identidade étnica ou cultural. Dourado (2012, p. 69) pede que os conhecimentos tradicionais sejam tratados como uma categoria jurídica, cujo delineamento foi iniciado por ensejo das discussões realizadas no contexto Convenção sobre Diversidade Biológica (CDB), a partir de 1992.

O legislador constitucional tratou dos conhecimentos tradicionais, no art. 216 da CF/88, como parte do patrimônio cultural brasileiro, referindo-se às formas de expressão; aos modos de criar, fazer e viver; às criações artísticas e tecnológicas, portadoras de referência à identidade, à ação e à memória dos diferentes grupos formadores da sociedade brasileira. Dourado (2012, p. 68) ainda esclarece que o Texto Maior trata dos conhecimentos tradicionais sob a perspectiva dos direitos humanos, classificando-os como direitos culturais.

Dourado (2012, p. 69) aponta que, dada à omissão do poder legislativo federal em distinguir as práticas culturais dos crimes contra a saúde pública, alguns municípios começaram a dispor sobre os ofícios cujas práticas tradicionais correspondem à afirmação de identidades coletivas. É o caso das leis dos municípios de São João do Triunfo e Rebouças, no Paraná, promulgadas respectivamente em 2010 e 2011, que trazem, como critério para o reconhecimento dos benzedores (as), remendeiros (as) e parteiras, a consciência de sua identidade de detentor de ofício tradicional de cura.

Por fim, Dourado (2012, p. 69) ressalta que estas leis reconhecem a importância dos ofícios tradicionais para a saúde pública nesses municípios e declaram as ervas e plantas nativas de uso medicinal como de livre acesso e de uso comum.

Lima (2020, p. 1021) pontua que em comunidades tradicionais é comum a utilização de plantas, ainda que com efeitos psicotrópicos, em rituais religiosos. Entretanto, é importante frisar que esta prática não constitui ilícito penal, pois, embora o art. $2^{\circ}$ de drogas Lei de Drogas (Lei ${ }^{\circ}$ 
11.343/06) tipifique, em todo o território nacional, o plantio, a cultura, a colheita e a exploração de vegetais e substratos dos quais possam ser extraídas ou produzidas drogas, são ressalvadas as hipóteses de autorização legal e regulamentar, bem como a utilização de plantas em rituais religiosos.

A Lei de Drogas está em consonância com a Convenção de Viena das Nações Unidas sobre Substâncias Psicotrópicas de 1971, da qual o Brasil é signatário. O art. 32 desta Convenção estabelece as ressalvas que os países podem fazer quanto suas substâncias psicotrópicas, e, sobre as substâncias utilizadas em rituais religiosos, é esclarecido que o Estado em cujo território cresçam plantas silvestres que contenham substâncias com efeitos psicotrópicos, e que são tradicionalmente utilizadas por pequenos grupos, nitidamente caracterizados, em rituais mágicos ou religiosos, poderá formular ressalvas em relação a tais plantas.

Lima (2020, p. 1021) esclarece que, mesmo na hipótese de uso de plantas em rituais religiosos, aind a é necessária autorização legal ou regulamentar. O autor traz como exemplo o chá Ayahuasca, produto da decacção do cipó Banisteriopsis caapi e da folha Psychotria viridis, bastante usado pelo movimento religioso conhecido como Santo Daime.

\section{O CURANDEIRISMO E O CHALATANISMO SOB A ÓPTICA DO DIREITO CONSTITUCIONAL CULTURAL}

Souza Jr. (2011, p. 36) assevera que o legislador constitucional prezou pela valorização do conhecimento tradicional, tendo em vista que reconheceu a necessidade de manutenção da autonomia dos povos tradicionais. Assim, a CRFB/88 expressou, em seu art. 215, que o Estado deve garantir a todos o pleno exercício dos direitos culturais, acesso às fontes da cultura nacional, apoio e incentivo a valorização e a difusão das manifestações culturais, protegendo as manifestações das culturas populares, indígenas e afro-brasileiras, assim como as de outros grupos participantes do processo civilizatório nacional.

$\mathrm{O}$ art. 216 da CRFB/88 estabelece que constituem patrimônio cultural brasileiro os bens de natureza material e imaterial, tomados individualmente ou em conjunto, portadores de referência à identidade, à ação, à memória dos diferentes grupos formadores da sociedade brasileira. Souza Jr. (2011, p. 36) conclui que a positivação dos direitos culturais na Carta Magna derrogou o crime de curandeirismo (artigo 284 do Código Penal), pois a proteção de práticas culturais se estenderia aos povos tradicionais. Caso a prática não tenha caráter tradicional e estiver sendo utilizada como método de cura, seria assim configurado o crime exercício ilegal da medicina, arte dentária ou 
farmacêutica (artigo 282 do Código Penal) ou até mesmo a prática se caracterizaria como charlatanismo (artigo 283 do Código Penal).

Entretanto, a jurisprudência é dissonante ao adotaruma postura ostensiva não aderente à tese de derrogação tácita do crime de curandeirismo. O Supremo Tribunal Federal (STF) entendeu que “qualquer princípio de crença a serviço da arte de curar é nocivo à saúde física e moral do povo e, portanto, constitui crime" (STF, Rel. Lafayette de Andrada, RT 310/746).

Outrossim, o Superior Tribunal de Justiça (SJT) já entendeu pela caracterização do crime de curandeirismo na hipótese em que o agente "ministrava passes e obrigava adultos e menores a ingerir sangue de animais e bebida alcoólica, colocando em perigo a saúde e levando os adolescentes à dependência do álcool” (REsp 1994/0019067-0, Rel. Min. Jesus Costa Lima, 5 Turma). O Tribunal de Justiça do Rio Grande do Sul chegou até a manifestar em um de seus julgados que "quem prescreve o uso de água fria, com a aposição de mãos e invocação de forças sobrenaturais, para cura de doença, pratica o curandeirismo, que é crime contra a saúde pública" (TJRS, Rel. Mário Boa Nova Rosa, RF 204/345).

\section{CONSIDERA ÇÕES FINAIS}

Com base no exposto, constata-se que o limite definido à liberdade de culto são o Direito à paz e à liberdade constitucional de crença, prezando sempre pela dignidade da pessoa humana e sendo vedados, assim, tratamentos religiosos cruéis que se utilizem de maus-tratos ou sacrifícios.

Em regra, os atos religiosos devem sem vistos como autênticas manifestações de fé, posto que, na grande maioria dos casos, são inofensivos à saúde pública. Os líderes religiosos que extrapolam os limites legais devem responder pelos crimes de charlatanismo, caso anunciem cura infalível para alguma patologia, mesmo cientes de que seus procedimentos não são idôneos para tanto. O mesmo procedimento se dará em relação ao curandeirismo, caso o agente acredite ser capaz de curar o doente, utilizando-se, para isso, de receitas especiais, tidas muitas vezes como mágicas.

Deve-se também levar em consideração a disponibilidade do indivíduo, buscand o sempre nortear-se pelos princípios da alteridade e principalmente pelo da razoabilidade. Caso a vítima tenha, como resultado, lesões corporais de natureza grave ou gravíssima ou vier a óbito, o agente deverá ser responsabilizado pelas lesões ou pelo delito de homicídio. Propõe-se a criação de um excludente de tipicidade para os povos tradicionais que, não tendo oferta de serviços de saúde pelo Estado, buscam sua cura em práticas curativas ofertadas por seus líderes religiosos. A utilização 


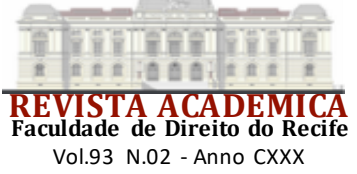

de plantas com efeitos psicotrópicos por povos tradicionais em rituais religiosos não constitui crime, pois é uma das ressalvas trazidas pela Lei de Drogas.

Apesar de alguns autores entenderem que os tipos penais de curandeirismo e charlatanismo devem ser revistos ou até mesmo que o delito de curandeirismo foi derrogado tacitamente pela CRFB/88, o atual posicionamento jurisprudencial vai na contramão de tal entendimento, tendo em vista que ainda buscam a responsabilidade criminal dos autores quando os julgam enquadrados neste tipo penal.

O legislador criou mecanismos de proteção da saúde pública, exigindo dos profissionais, a necessária apresentação de registros nos conselhos de classe, não impedind oque as igrejas prestem serviços na área, mas restringindo esta atuação somente aos profissionais qualificados. Deve-se também, por parte do poder público, informar aos fiéis quanto aos atos mais comuns na prática de tais delitos, buscando esclarecer que é justo recorrer a fé como solucionadora de problemas, mas sempre devendo analisar se o líder religioso está agindo de boa-fé.

A tolerância não significa renunciar às próprias convicções ou mesmo ao direito de convencer os outros a respeito delas, contudo é necessário que se busquem alternativas pela via do diálogo, da persuasão racional e do livre arbítrio, sem que haja imposições.

\section{REFERÊNCIAS}

AGRA, Walber de Moura. Curso de Direito Constitucional. 9. ed. Belo Horizonte: Fórum, 2018. 216-218 p.

ANDRADE, Luiz Gustavo de; QUINTÃO, Bruna de Oliveira. Liberdade de religião e de escolha do tratamento médico e o dever de preservação da vida-uma análise a partir da colisão de direitos fundamentais. Revista Juridica, v. 27, n. 11, p. 119-144, 2011.

BOBBIO, Norberto. A era dos direitos. Rio de Janeiro: Elsevier, 2004. 14 p.

BRASIL. Constituição (1988). Constituição da República Federativa do Brasil. Brasília, DF: Senado Federal: Centro Gráfico, 1988.

BRASIL. Decreto-Lei 9.099, de 26 de setembro de 1995. Lei dos Juizados Especiais Cíveis e Criminais. Diário Oficial da República Federativa do Brasil, Poder executivo, Brasília DF, 27 set. 1995 .

BRASIL. Decreto-Lei 2.848, de 07 de dezembro de 1940. Código Penal. Diário Oficial da União, Poder executivo, Rio de Janeiro, 31 dez. 1940.

BRASIL. Decreto-Lei 11.343, de 23 de agosto de 2006. Lei de Drogas. Diário Oficial da República Federativa do Brasil, Poder executivo, Brasília DF, 24 de agosto de 2006. 


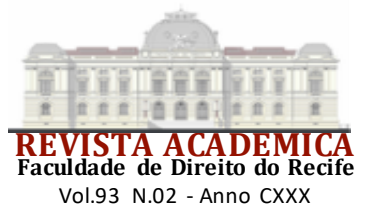

BRASIL. Decreto n. 6.040 de 07 de fevereiro de 2007. Política Nacional de Desenvolvimento Sustentável dos Povos e Comunidades Tradicionais. Diário Oficial, Brasília, 07 fev. 2007.

CANOTILHO, José Joaquim Gomes; MENDES, Gilmar Ferreira; SARLET, Ingo Wolfgang; STRECK, Lenio Luíz; LEONCY, Leo Ferreira. Comentários a Constituição do Brasil. 2. ed., São Paulo: SaraivaJus, 2018. p. 543-555.

DOURADO, Sheilla Borges. Conhecimentos tradicionais e direitos humanos. In: REUNIÃO ANUAL DA SBPC, 64., 2012, São Luís. Anais [...]. São Luís/MA: UFMA 2012. p. 48-69. v. 29.

DURKHEIM, Émile. As Formas elementares da vida religiosa. São Paulo: Martins Fontes, 2003. 32 p.

FREITAS, Marco Antônio Barbosa de; COHN, Amélia; PINTO, Rosa Maria Ferreiro. O universo da discutível universalidade do Sistema Único de Saúde. Revista Acadêmica da Faculdade de Direito do Recife, v. 90, n. 1, 2018. p. 48-69.

GIMENES, Nilson Roberto da Silva. Bullying religioso na escola e a responsabilidade civil. Revista Acadêmica da Faculdade de Direito do Recife, v. 87, n. 2, 2015. p. 138-162.

LIMA, Renato Brasileiro de. Legislação Criminal Especial Comentada. 8. ed. atual. [S. 1.]: Juspodvm, 2020. 1021 p. Volume único.

MARGOTTA, Roberto. História ilustrada da medicina. 1. ed. São Paulo: Editora Manole, 1998. $122 \mathrm{p}$.

MEHLMAN, Maxwell J. Quackery. American journal of law \& medicine, v. 31, n. 2-3, p. 349-363, 2005.

MENDES, Gilmar Ferreira; BRANCO, Paulo Gustavo Gonet. Curso de Direito Constitucional. 16. ed. São Paulo: SaraivaJus, 2021. p. 447-448.

MIRANDA, Carlos Alberto Cunha. A arte de curar nos tempos da colônia: limites e espaços da cura. 3. ed. Recife. Ed. Universitária da UFPE, 2017. p. 21-22.

MORAES, Alexandre de. Direito constitucional. 34. ed. São Paulo: Atlas, 2018. 88 p.

MORAIS, Márcio Eduardo Pedrosa. Religião e direitos fundamentais: o princípio da liberdade religiosa no estado constitucional democrático brasileiro. Revista Brasileira de Direito Constitucional, v. 18, n. 1, p. 225-242, 2011.

NASCIMENTO, Monica Pinchemel; MARTINS, Paulo Cezar Borges. Alternativas populares à medicina oficial: Assistência à saúde e religiões de matriz africana. Revista Fragmentos de Cultura-Revista Interdisciplinar de Ciências Humanas, Goiânia, v. 29, n. 4, p. 697-707, jul. 2020.

PANASIEWICZ, Roberlei. Pluralismo religioso contemporâneo. Diálogo inter-religioso na teologia de Claude Geffré. 2. ed. São Paulo: Paulinas; Belo Horizonte: Editora PUC Minas, 2010. 127 p. 


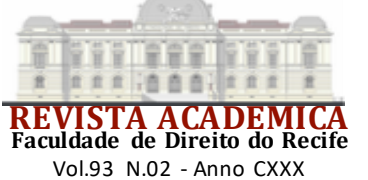

PORTER, Roy. Cambrigde - História da Medicina. 1. ed. São Paulo: Thieme Revinter, 2008. p. $13 ; 223-225$.

PUTTINI, Rodolfo Franco. Curandeirismo, curandeirices, práticas e saberes terapêuticos: reflexões sobre o poder médico no Brasil. Revista de Direito Sanitário, v. 11, n. 3, p. 32-49, 2011.

SARLET, Ingo Wolfgang. Notas acerca da liberdade religiosa na Constituição Federal de 1988. Revista Direito UFMS, v. 1, n. 1, p. 87-102, 2015.

SILVA. J. Martins e. A medicina na Mesopotâmia Antiga. Acta Med Port. 2009. p. 841-854. v. 22.

SILVA, Mariana Lins de Carli. Curandeirismo: o bem jurídico saúde pública a serviço de uma política criminal racista. Revista Brasileira de Ciências Criminais, v. 152, n. 2019, p. 145-171, 2019.

SOBREIRA, Ramon Fiori Fernandes; MACHADO, Carlos José Saldanha; VILANI, Rodrigo Machado. A Criminalização das religiões afro-brasileiras. Revista Direitos Culturais, Santo Ângelo, v. 11, n. 23, p. 143-145, jan./abr. 2016.

SOUZA JR, Hailton Pinheiro de. Proteção ao conhecimento tradicional associado e crime de curandeirismo: Breves considerações. Revista de Direito da Unigranrio, v. 4, n. 1, p. 31-43, 2011.

VILLA, Marco Antônio. A história das constituições brasileiras: 200 anos de luta contra o arbítrio. São Paulo: Leya, 2011. p. 20. 